\title{
Influence of Firing Temperature on Properties of Gun Propellants
}

\author{
Karim Moulai Boulkadid ${ }^{1 *}$, Michel Lefebvre ${ }^{1}$, Laurence Jeuniea $^{1}$ and Alain Dejeaifve ${ }^{2}$ \\ 1. Laboratory for Energetic Materials, RMA, Brussels 1000, Belgium \\ 2. PB Clermont SA, Engis 4480, Belgium
}

\begin{abstract}
Initial firing temperatures play an important role on the combustion rate of propellant. In gun propellants, initial temperature is a key factor for both accuracy and safety. Ideally, the initial temperature of the propellant should not influence the ballistic properties of the round. Nevertheless, constant initial temperature coefficients can not be achieved easily. This work focuses on the influence of the firing temperature on the ballistic properties, the mechanical integrity and the sensitivity to impact of nitrocellulose based propellants. Combustion rates have been determined by closed vessel tests. Ballistic properties have been investigated by firing 5.56 cartridges. The propellants have been conditioned at temperatures ranging from $-54{ }^{\circ} \mathrm{C}$ to $+71^{\circ} \mathrm{C}$ before firing. The largest temperature coefficient is observed at high temperatures. The temperature sensitivity of the peak pressure in the combustion chamber can not be fully explained by the results from the closed vessel test. The authors speculated that the mechanical behaviour of the propellant grains at low temperatures influences also the overall ballistic properties of the round. Impact tests with propellants conditioned at low and high temperatures permit to investigate their mechanical strength under extreme temperatures and to better understand the propellant performance during firing. Tests on aged propellants have been conducted as well.
\end{abstract}

Key words: Firing temperature, gun propellant, ageing, ballistic firing, closed vessel tests, impact tests.

\section{Introduction}

Small caliber weapon systems are used widely as spherical and flattened propellants and are designed to operate safely over a variety of environmental conditions. NATO (North Atlantic Treaty Organization) requires the munitions to be usable from $-51{ }^{\circ} \mathrm{C}$ (category of climate $\mathrm{C} 3$ ) to $+63{ }^{\circ} \mathrm{C}$ (category of climate A1/B3). A basic aim in gun propulsion research is to have constant ballistic behaviour of the propellant, namely constant maximal pressure, highest controlled projectile velocity over the entire operational range of the environmental temperatures. Indeed, if the authors get rid of the temperature sensitivity of the gun propellant, the munitions can be fired at maximal pressure over the entire operational range of the environmental temperatures and performances would not be lost at

\footnotetext{
*Corresponding author: Karim Moulai Boulkadid, Ph.D. student, research field: energetic materials. E-mail: karim.boulkadid@gmail.com.
}

normal ambient temperature (around $+20{ }^{\circ} \mathrm{C}$ ) where usually firings occur.

The temperature sensitivity of the maximal pressure and the projectile velocity can be adversely influenced by the temperature sensitivity of the propellant combustion rate. The combustion rate of the propellant increases with the initial temperature of the propellant (shown in the part of 4.1.1). This leads to an increase of the maximal pressure in the weapon with the initial temperature of the propellant. Moreover, other parameters influencing the temperature sensitivity of the maximal pressure and the projectile velocity include, but are not limited to: propellant grain geometry, deterrent layers coating, propellant loading density, grain fracture, especially at cold temperatures, grain softening at high temperatures, projectile mass [1]. Experimental ballistic studies on the behaviour of the propellants at distinct initial temperatures of the propellant have been published by some authors [2, 3], but there is no 
wide investigation on this matter.

This paper therefore presents a study of the effects of the initial temperature of the propellant on ballistics, mechanical properties and impact sensitivity of a deterred spherical gun propellant. The main purpose is to correlate the propellant performance observed during firing to experiments from the laboratory, in this case closed vessel and BAM (German Bundesanstalt fur Materialprufung)-fallhammer.

\section{Experimental Methods}

The determination of the combustion rate and internal ballistic properties of the tested propellant are based on closed vessel tests and firing of 5.56 cartridges. The mechanical properties of the propellant at low and high temperatures have been investigated using BAM-fallhammer impact apparatus.

All tests have been performed at initial temperatures ranging from $-54{ }^{\circ} \mathrm{C}$ to $+71^{\circ} \mathrm{C}$, which is relevant for military use of the propellant.

\subsection{Combustion Rate}

Whereas a surface element dS belonging to a piece of burning grain propellant (Fig. 1). The gases are released according to normal $\mathrm{x}$. The combustion surface progresses in parallel to itself. The rate of the progression of the combustion surface is termed "combustion rate".

The combustion rate is determined experimentally. The most convenient method is by closed vessel tests.

Closed vessel experiments are performed in a vessel of $118 \mathrm{~cm}^{3}$ for three different initial temperatures of the propellant: $-54{ }^{\circ} \mathrm{C},+21{ }^{\circ} \mathrm{C}$ and $+71^{\circ} \mathrm{C}$. The propellant loading density is $0.15 \mathrm{~g} / \mathrm{cc}$. Pressures are recorded using piezo-electric transducer Kistler 6215. The output voltage of the pressure sensor is transmitted to a data acquisition system with a sampling rate of $250 \mathrm{kHz}$. The propellant is ignited using a gaseous $\mathrm{CH}_{4}-\mathrm{O}_{2}$ mixture [4]. This ignition procedure ensure homogeneous ignition of the propellant charge inside the vessel. The propellant

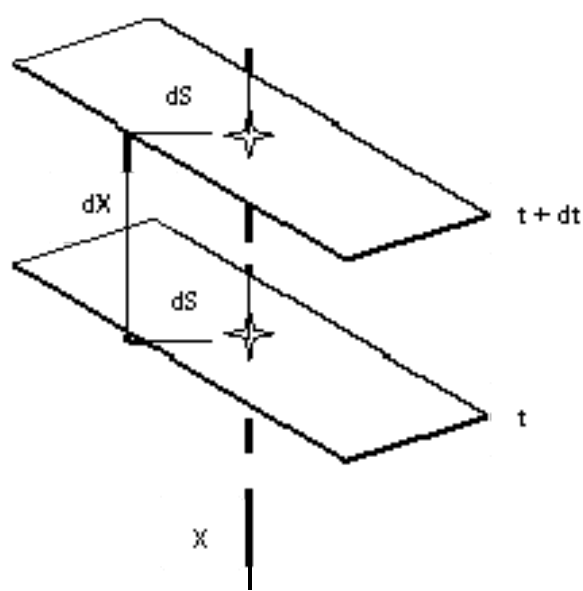

Fig. 1 Definition of the combustion rate.

charges are initially conditioned for at least $8 \mathrm{~h}$ at its firing temperature.

A typical pressure record and its corresponding derivative are given in Fig. 2a and Fig. 2b, respectively. The combustion rate shown in Fig. 3 is calculated according to STANAG 4115 [5]. Two phases are observed in the derivative of the pressure versus time and in the calculated combustion rate: the deterred and the not deterred part of the propellant [6]. These two parts are emphasized by dotted lines in Figs. 2 and 3.

Only the combustion rates at $40 \mathrm{MPa}$ and $100 \mathrm{MPa}$ will be discussed in this paper and correspond to the combustion occurring in the deterred and the not deterred part of the propellant, respectively.

\subsection{Internal Ballistic Properties}

The gun firings are performed in a EPVAT test barrel 5.56 NATO (Fig. 4) utilizing an ammunition containing a lead primer. A mass of $1.7 \mathrm{~g}$ of the propellant is poured into a standard $5.56 \times 45 \mathrm{~mm}$ cartridge. The corresponding loading density is $0.92 \mathrm{~g} / \mathrm{cc}$. All rounds are shot for four different values of the initial temperature of the propellant: $-54{ }^{\circ} \mathrm{C}$, $-20^{\circ} \mathrm{C},+21^{\circ} \mathrm{C}$ and $+71^{\circ} \mathrm{C}$. Propellant charges were conditioned for a minimum of $14 \mathrm{~h}$ and fired immediately after being removed from the conditioning cabinet (time from removing out of the cabinet to actual firing: 2 min maximum). The maximal pressure 


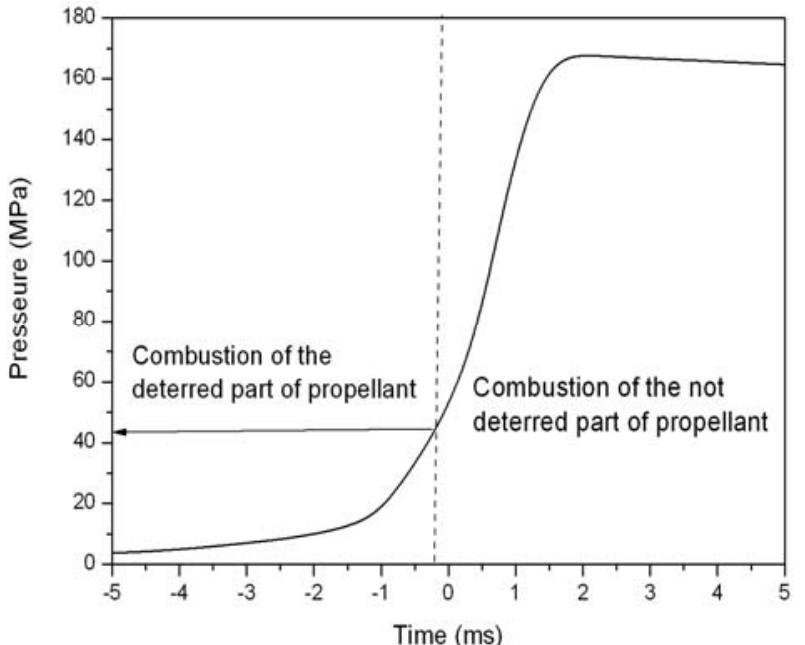

(a)

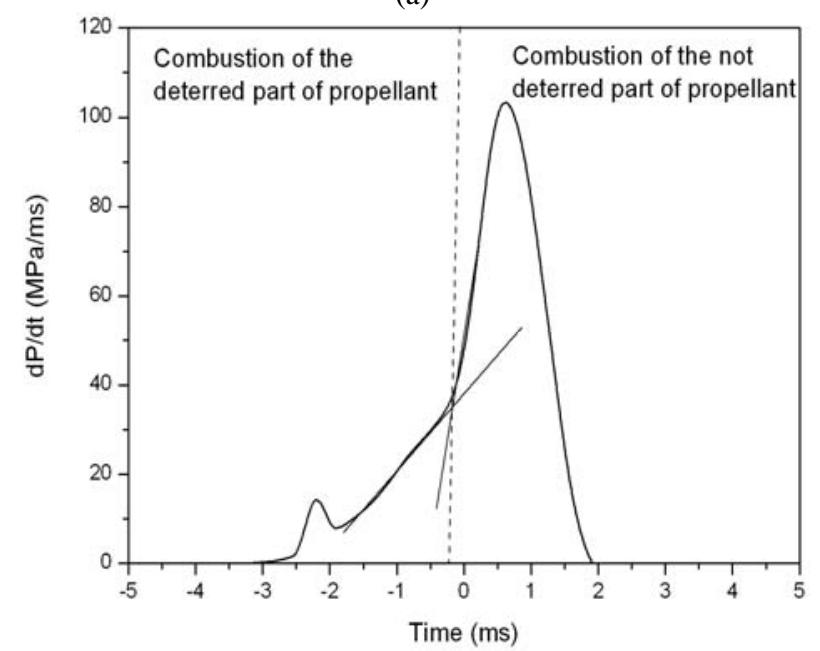

(b)

Fig. 2 (a) Example of pressure history in the closed vessel (case of an unaged propellant at $+21^{\circ} \mathrm{C}$ ); (b) Derivative of pressure vs. time.

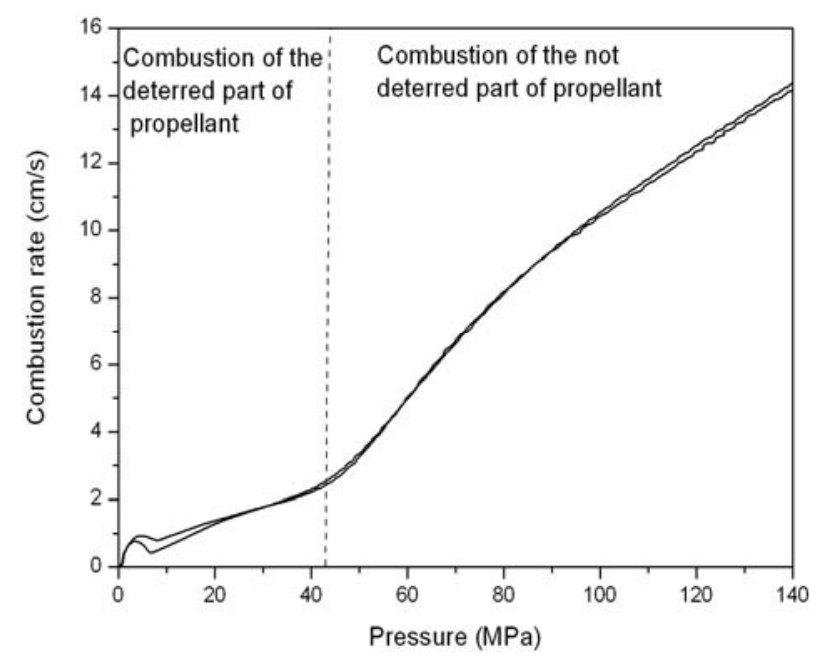

Fig. 3 Combustion rate as a function of the pressure, case of an unaged propellant at $+21^{\circ} \mathrm{C}$ ( 2 shots). inside the cartridge and the projectile velocity will be discussed in this paper.

\subsubsection{Chamber Pressure}

Piezo-electric pressure transducers Kistler 6215 are used to record the pressure inside the cartridge case (Fig. 4b, the hole in the case is visible) and at the case mouth. The total record time of the pressure is equal to $4 \mathrm{~ms}$ at a sampling rate of $5,000 \mathrm{kHz}$.

Fig. 5 shows a typical record of the pressure inside the cartridge for the investigated deterred propellant and for comparison purpose for a double base propellant. It can be observed that for the deterred

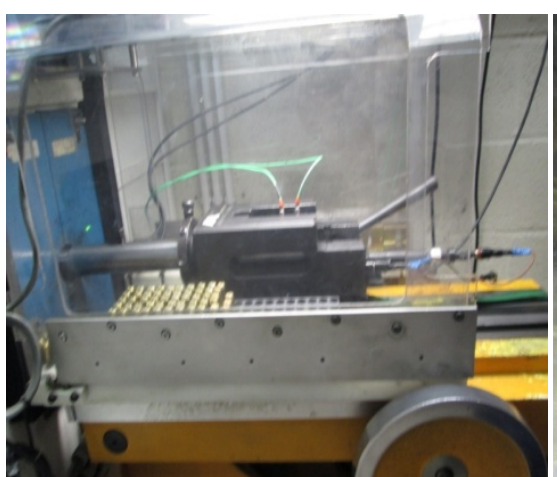

(a)

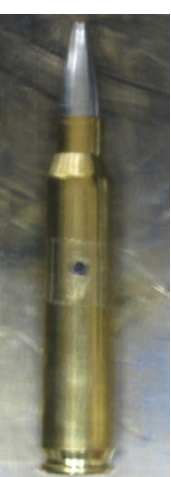

(b)
Fig. 4 (a) Gun equipped with the piezo-electric transducer Kistler 6215, and (b) pierced cartridge showing the location for the pressure gauge.

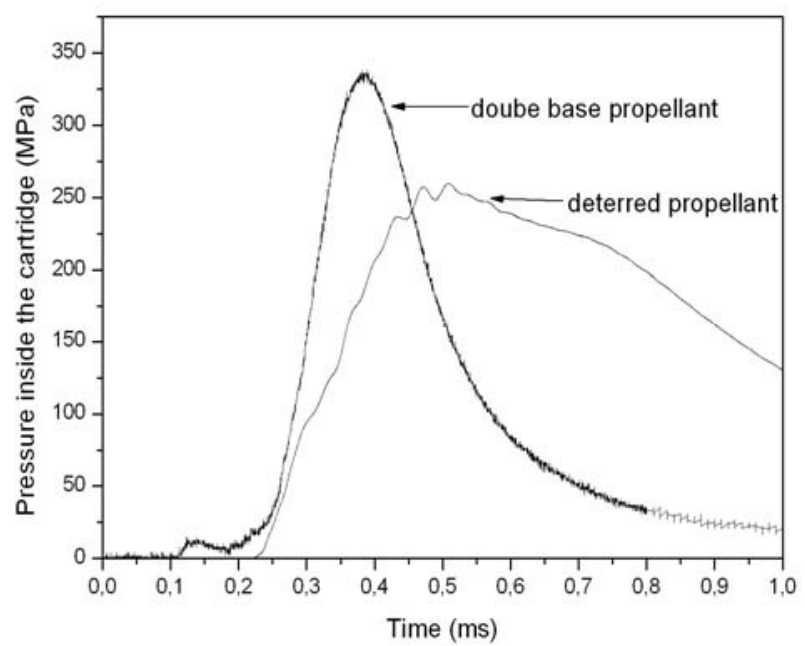

Fig. 5 Example of pressure time curves for the deterred propellant (this investigation) measured in the cartridge (unaged propellant fired at $+21{ }^{\circ} \mathrm{C}$ ) and for a double base propellant (archives, for comparison purpose) fired in a $\mathbf{5 0}$ inch weapon for a loading density of $0.6 \mathrm{~g} / \mathrm{cm}^{3}$, the pressure is also measured inside the cartridge. 
propellant, the pressure build up is more progressive and the pressure stay at its maximal value for a greater time than for a not deterred propellant. This is due to the typical action of the deterrent in surface [7]: In the early phase of the combustion, the combustion rate is low but the propellant surface is high. At the end phase of the combustion, when the deterred layers of the propellant grains are burnt, the combustion rate is higher but the propellant surface is smaller. As a result, the gas generation rate stays more or less constant.

\subsubsection{Projectile Velocity}

The projectile velocity at the muzzle is measured as well. The precise detection of the muzzle exit of the projectile is done by means of a B617 Muzzle Flash Detector. The flash detector is installed at $1 \mathrm{~m}$ on the side of the muzzle of the barrel. The trigger for the measurement occurs exactly when the firing pin touches the primer. B471 Precision Light Screen placed at a distance of $24 \mathrm{~m}$ from the muzzle determines projectile velocity by measuring the time $(t)$ required to travel a known distance between two infrared sensors area $(1,000 \times 600 \mathrm{~mm})$.

\subsection{Impact Tests}

The sensitivity of gun propellant gun is assessed by impact test, friction test and electrostatic sensitivity test.

In the early phase of the combustion inside cartridge, the blast pressure waves produced by ignition of the primer placed at the base of the propellant bed may accelerate propellant grains forward to impact the projectile base. By consequent, the authors choose to perform impact tests as the propellant grains are submitted to a similar stimulus during ballistic firing.

Impact tests were carried out by means of the standard BAM-fallhammer apparatus. The impact device consists of two coaxially arranged steel cylinders held in place by a cylindrical steel guide ring. Among equivalent to $40 \mathrm{~mm}^{3}$ of the propellant were placed inside the impact device. Drop weights of 1 and $5 \mathrm{~kg}$ are used for testing.

\subsubsection{Impact Sensitivity Tests}

Typically, the Fallhammer test is used for the determination of the impact sensitivity of energetic materials. In a first set of experiments, the authors indeed determined the impact sensitivity of the propellants at normal, low and high temperatures. Various procedures exist for the determination of the sensitivity level: "1-out-of-6-reaction-level" is the most common one [8]. As this assessment method lacks statistical background, the authors used the Bruceton method [9]. The Bruceton method allows to determine the energy level, $\mathrm{E}_{50}$ (or drop height, $\mathrm{H}_{50}$ ) at which there is $50 \%$ probability of obtaining a reaction. Energy level, $\mathrm{E}_{50}$ has been determined at three values of the initial temperature of the propellant: $-54{ }^{\circ} \mathrm{C}$, $+21{ }^{\circ} \mathrm{C}$ and $+71{ }^{\circ} \mathrm{C} . \mathrm{H}_{50}$ will be discussed in this paper.

\subsubsection{Mechanical Properties}

The Fallhammer will also be used in this study to characterize the mechanical properties of the propellant. The results from the determination of the impact sensitivity establish an energy threshold below which no reaction will occur. Using impact energies lower than this threshold enables us to dynamically stress the propellant grain and to observe its response to the mechanical stimuli. The authors selected weight of $1 \mathrm{~kg}$, placed at a high of $10 \mathrm{~cm}$, corresponding to an energy level of 1 Joule. The mechanical response of the propellant grain to the stimulus of the falling weight is assessed by measuring the grain deformation. The diameter of the 50 grains before and after impact is measured using a comparator in order to determine the grain size distribution. Comparison between both size distributions permits to evaluate the effect of the mechanical stimulus on the grain geometry. Impact tests have been carried out for three initial temperatures of the propellant: $-54{ }^{\circ} \mathrm{C},+21{ }^{\circ} \mathrm{C}$ and $+71{ }^{\circ} \mathrm{C}$. Conditioning of the cylinders and steel collars containing the propellant is performed for at least $8 \mathrm{~h}$. It is important to note that the energy levels are always 


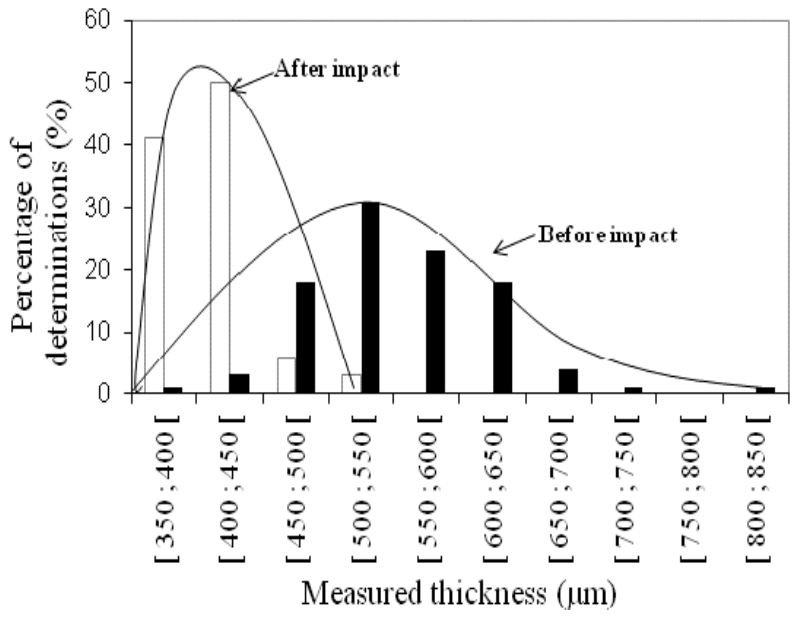

Fig. 6 Example of grain size distributions of unaged propellant at $+21^{\circ} \mathrm{C}$ before and after impact.

chosen to prevent the sample to react. Fig. 6 shows a typical example of the grain size distribution of unaged propellant before and after impact, at $+21^{\circ} \mathrm{C}$.

This method permits to determine the shape modification of the propellant due to compression and therefore gives insight on the mechanical properties of the propellant. The difference between the average thickness of propellant grain before and after impact is named " $\Delta$ thickness". This value will be discussed in this paper.

\section{Tested Propellant}

A spherical deterred double base propellant is used for this investigation. The initial propellant grain has an average diameter of $553 \mu \mathrm{m}$. It contains around $10 \%$ of nitroglycerin and is stabilised with DPA (diphenylamine). The average concentration of the deterrent (dibutylphtalate) is $4.8 \%$. For each type of tests, Table 1 summarizes the investigated physical/chemical properties and the temperatures at which the propellants have been conditioned before testing.

The propellant has been aged at a temperature of $+71{ }^{\circ} \mathrm{C}$ for time duration ranging from 10 to 70 days (Table 2).

\section{Results}

\subsection{Combustion Rate}

\subsubsection{Unaged Propellant}

Fig. 7 shows the combustion rate at $40 \mathrm{MPa}$ and $100 \mathrm{MPa}$ as a function of the initial temperature of the propellant. The pressures $40 \mathrm{MPa}$ (low pressure) and $100 \mathrm{MPa}$ (high pressure) correspond to the combustion occurring in the deterred and the not deterred part of the propellant, respectively. The combustion rate of the deterred and the not deterred part of the propellant increased as the initial temperature of the propellant increases.

\subsubsection{Aged Propellant}

Fig. 8 shows the variation of the combustion rate at $40 \mathrm{MPa}$ and $100 \mathrm{MPa}$ as a function of ageing time for

Table 1 Initial temperatures of the propellant for the different performed tests.

\begin{tabular}{|c|c|c|c|c|c|}
\hline \multirow{2}{*}{ Tests } & \multirow{2}{*}{ Investigated property } & \multicolumn{4}{|c|}{ Initial temperature $\left({ }^{\circ} \mathrm{C}\right)$} \\
\hline & & -54 & -20 & +21 & +71 \\
\hline Closed vessel & Propellant burning rate & $\checkmark$ & & $\checkmark$ & $\checkmark$ \\
\hline \multirow{2}{*}{ Gun firing } & Chamber pressure & $\checkmark$ & $\checkmark$ & $\checkmark$ & $\checkmark$ \\
\hline & Projectile velocity & $\checkmark$ & $\checkmark$ & $\checkmark$ & $\checkmark$ \\
\hline \multirow{2}{*}{ Fallhamer } & Impact sensitivity & $\checkmark$ & & $\checkmark$ & $\checkmark$ \\
\hline & Mechanical response & $\checkmark$ & & $\checkmark$ & $\checkmark$ \\
\hline
\end{tabular}

Table 2 Ageing plan (in days) of the investigated propellant and carried out experiments.

\begin{tabular}{lllll}
\hline Experiments & \multicolumn{2}{l}{ Ageing time (days) } & & \\
\cline { 2 - 4 } & & 0 & 10 & $\checkmark$ \\
Closed vessel & $\checkmark$ & $\checkmark$ & $\checkmark$ & $\checkmark$ \\
Gun firing & Impact sensitivity & $\checkmark$ & $\checkmark$ & $\checkmark$ \\
\hline \multirow{2}{*}{ Fallhammer } & Mechanical response & $\checkmark$ & $\checkmark$ \\
\hline
\end{tabular}




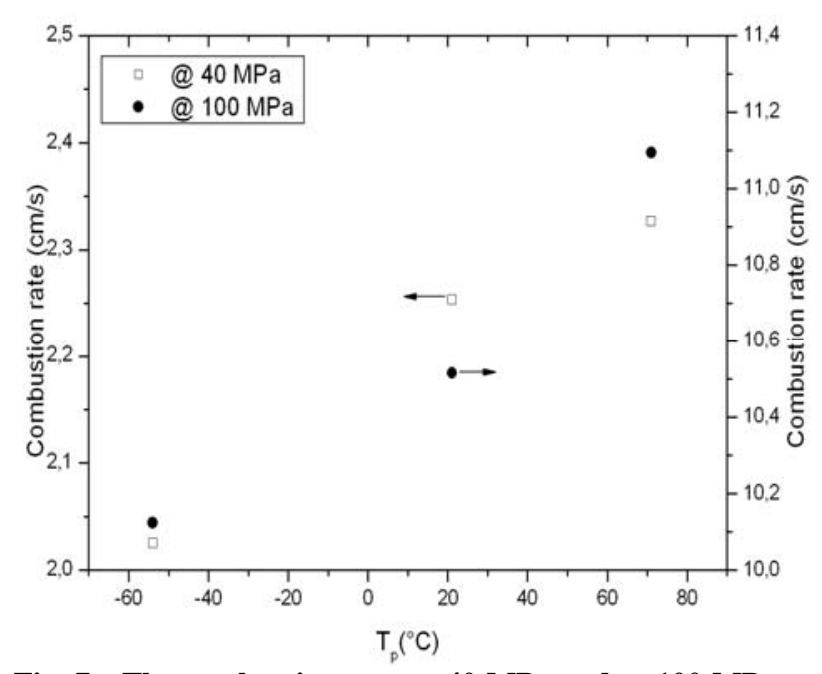

Fig. 7 The combustion rate at $40 \mathrm{MPa}$ and at $100 \mathrm{MPa}$ as a function of the initial temperature.

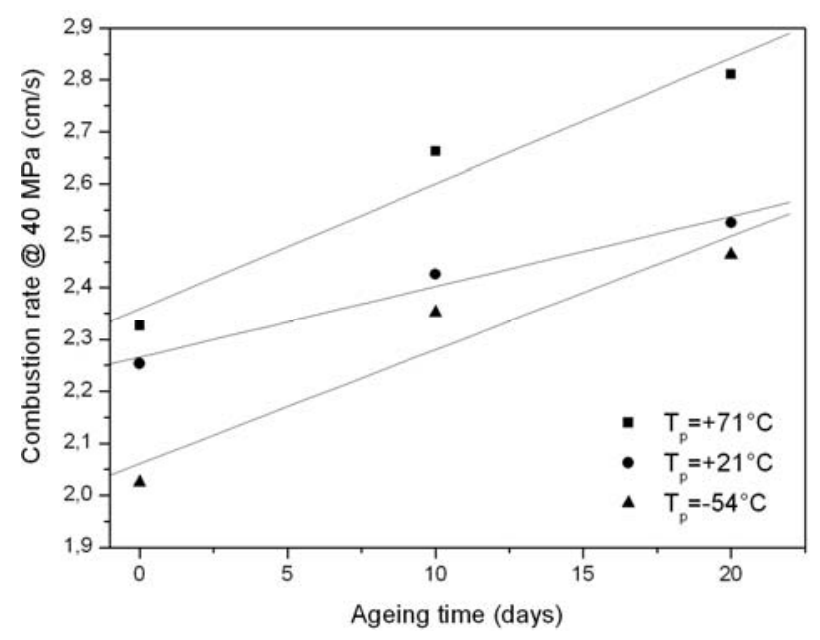

(a)

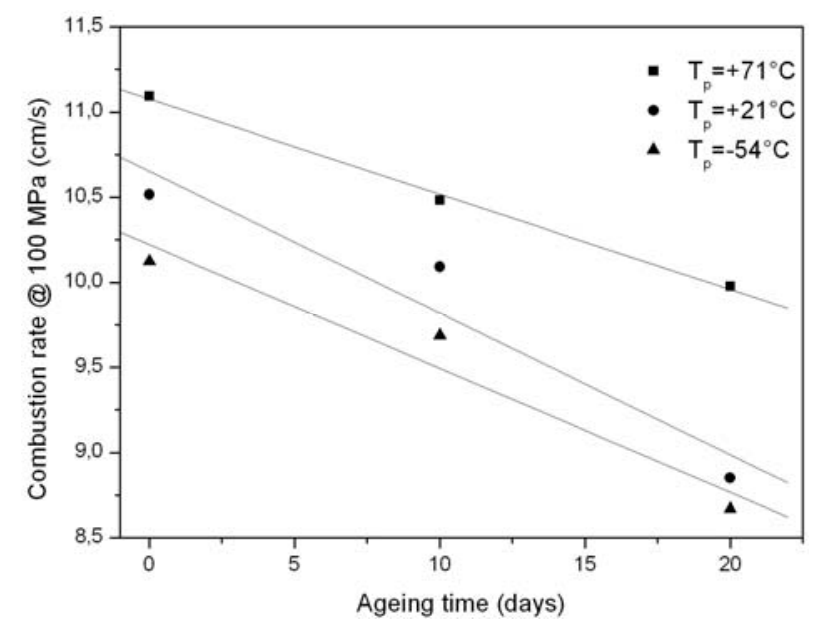

(b)

Fig. 8 Variation of the combustion rate at (a) $40 \mathrm{MPa}$ and at (b) $100 \mathrm{MPa}$ as a function of the ageing time for three different values of the initial temperature of the propellant. three values of the initial temperature of the propellant. At low (40 MPa) and high (100 MPa) pressure which is respectively correspond to the combustion of the deterred and the not deterred part of the propellant.

The combustion rate decreases as the initial temperature of the propellant decreases. The combustion rate at $40 \mathrm{MPa}$ increases with ageing, while the combustion rate at $100 \mathrm{MPa}$ decreases with ageing. These variations are explained by the deterrent migration [10]: the increase of the combustion rate at low pressure (40 $\mathrm{MPa})$ and the decrease of the combustion rate at high pressure $(100 \mathrm{MPa})$ are due to the decrease of the deterrent concentration near the surface and the increase of the deterrent concentration in the centre part of the propellant, respectively.

4.1.3 Temperature Coefficient of the Combustion Rate

The temperature coefficient of the combustion rate of the propellant is the response of the combustion rate of the propellant to changes in the initial propellant temperature. When the change of the initial temperature is between $+21^{\circ} \mathrm{C}$ and $+71{ }^{\circ} \mathrm{C}$, the response of the propellant to this change is termed "hot temperature coefficient". The response of the combustion rate of the propellant to change in the initial propellant temperature between $+21^{\circ} \mathrm{C}$ and $-54{ }^{\circ} \mathrm{C}$ is called "cold temperature coefficient". The hot and the cold propellant temperature coefficients can be respectively calculated using Eqs. (1 and 2):

Hot temperature coefficient

$$
=\frac{\mathrm{r}\left(\mathrm{Tp}=+71^{\circ} \mathrm{C}\right)-\mathrm{r}\left(\mathrm{Tp}=+21^{\circ} \mathrm{C}\right)}{71-21}
$$

Cold temperature coefficient

$$
=\frac{\mathrm{r}\left(\mathrm{Tp}=+21^{\circ} \mathrm{C}\right)-\mathrm{r}\left(\mathrm{Tp}=-54^{\circ} \mathrm{C}\right)}{21+54}
$$

where, $r$ is the combustion rate at constant pressure.

Values of the hot and cold temperature coefficients of the combustion rate of the investigated propellant at $40 \mathrm{MPa}$ and $100 \mathrm{MPa}$ before and after ageing are summarized in Table 3. One notices that largest 
Table 3 Hot and cold temperature coefficients of the combustion rate of the investigated propellant at $40 \mathrm{MPa}$ and $100 \mathrm{MPa}$ before and after ageing.

\begin{tabular}{lllll}
\hline Ageing time (days) & $\begin{array}{l}\text { Hot temperature } \\
\text { coefficient at } 40 \mathrm{MPa} \\
\left(\mathrm{mm} / \mathrm{s} /{ }^{\circ} \mathrm{C}\right)\end{array}$ & $\begin{array}{l}\text { Cold temperature } \\
\text { coefficient at } \\
40 \mathrm{MPa}\left(\mathrm{mm} / \mathrm{s} /{ }^{\circ} \mathrm{C}\right)\end{array}$ & $\begin{array}{l}\text { Hot temperature } \\
\text { coefficient at } 100 \mathrm{MPa} \\
\left(\mathrm{mm} / \mathrm{s} /{ }^{\circ} \mathrm{C}\right)\end{array}$ & $\begin{array}{l}\text { Cold temperature } \\
\text { coefficient at } 100 \mathrm{MPa} \\
\left(\mathrm{mm} / \mathrm{s} /{ }^{\circ} \mathrm{C}\right)\end{array}$ \\
\hline 0 & 0.015 & 0.030 & 0.116 & 0.052 \\
10 & 0.047 & 0.001 & 0.078 & 0.054 \\
20 & 0.057 & 0.008 & 0.225 & 0.024 \\
\hline
\end{tabular}

temperature coefficients of the combustion rate are observed in the range of the high temperatures.

\subsection{Internal Ballistic Properties}

Ballistic experiments were accomplished with propellants unaged and aged with its cartridge. The values-pressure inside the cartridge and velocity of the projectile are determined as a function of initial temperature of the propellant and of the ageing time.

\subsubsection{Unaged Cartridges}

The usual behavior of propellants during a ballistic cycle, when fired over the temperature range of $+70{ }^{\circ} \mathrm{C} /+60{ }^{\circ} \mathrm{C}$ to $-40{ }^{\circ} \mathrm{C} /-50{ }^{\circ} \mathrm{C}$ is a gradual decrease in the maximal pressure inside the cartridge as the initial temperature of the propellant decreases [2]. As a result of the decrease of the combustion rate as the initial temperature of the propellant decreases (Fig. 7).

During our investigation, this monotonous decrease of $\mathrm{P}_{\max }$ with the firing temperature is not fully observed. Two different types of variations of the maximal pressure are observed (Fig. 9).

-In the range of the high temperatures $\left(+71{ }^{\circ} \mathrm{C} /+21{ }^{\circ} \mathrm{C}\right)$, the maximal pressure inside the cartridge decreases as the initial temperature of the propellant decreases.

- In the range of the cold temperatures $\left(+21{ }^{\circ} \mathrm{C} /-54{ }^{\circ} \mathrm{C}\right)$, a nearly constant variation of the maximal pressure is noticed. At low temperature, the blast pressure waves produced by the ignition of the primer placed at the base of the propellant bed may accelerate propellant grains forward to impact the projectile base resulting in grain fracture. Consequently the burning surface will increase, compensating for the decrease in the combustion rate of the propellant when the temperature decreases (Fig. 7).

The projectile velocity shows a gradual decrease as the initial temperature decreases (Fig. 10). The decrease of the projectile velocity is sharper between $+71{ }^{\circ} \mathrm{C}$ and $+21^{\circ} \mathrm{C}$ than between $+21^{\circ} \mathrm{C}$ and $-54{ }^{\circ} \mathrm{C}$.

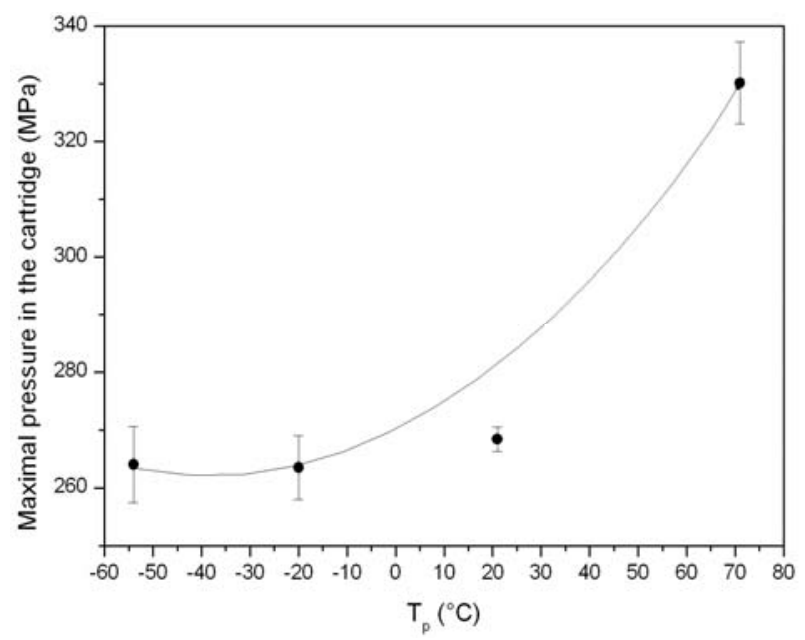

Fig. 9 Variation of the maximal pressure inside the cartridge as a function of the initial temperature of the propellant (unaged propellant, 10 shots). The displayed error bars are +1 SD (standard deviation).

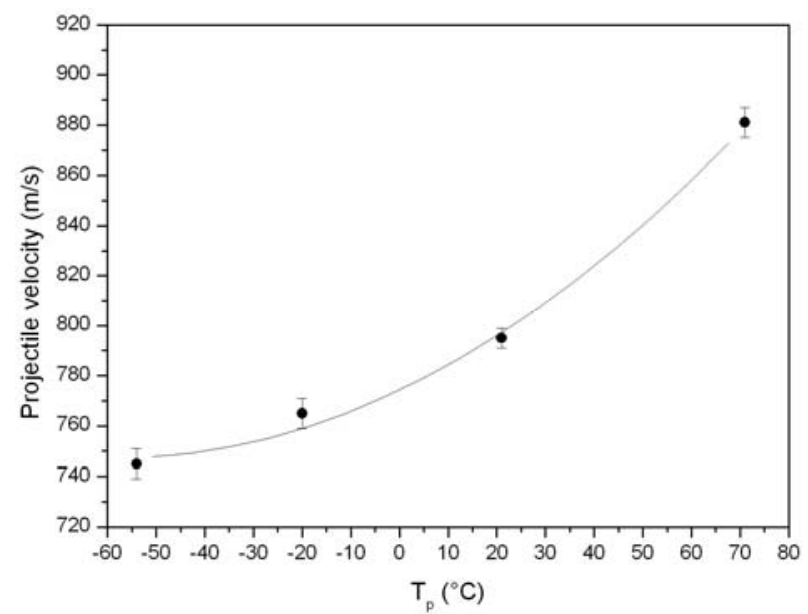

Fig. 10 Variation of the projectile velocity as a function of the initial temperature of the propellant (unaged propellant, 10 shots). The displayed error bars are +1 standard deviation. 
Fig. 11a shows the pressure history inside the cartridge at four values of the initial temperature of the propellant. The area under the pressure time curve is calculated by integrating the pressure time curve from $\mathrm{t}=0 \mathrm{~ms}$ to the barrel time (the time that the projectile needs to leave the muzzle). The plot of the area under the pressure time curve versus the projectile velocity (Fig. 11b) shown that the projectile velocity is proportional to the area under the pressure time curve.

Due to the increase of the combustion rate with the initial temperature of the propellant (Fig. 7), the pressure gradient at the beginning of the combustion in the pressure time curve (Fig. 11a) is faster and the maximal pressure is higher at $+71^{\circ} \mathrm{C}$. It is likely that at high temperature all the propellant is burnt when the projectile left the muzzle. At ambient and low temperatures, it could be that a fraction of the propellant is still unburnt when the projectile left the muzzle. The fraction becomes greater as the initial temperature of the propellant decreases; this is due to the decrease of the combustion rate with the initial temperature of the propellant. By consequence, the time to achieve a complete combustion decreases as the initial temperature of the propellant increases and the projectile velocity drops at low temperatures.

As the drop in the combustion rate is larger between $+71{ }^{\circ} \mathrm{C}$ and $+21{ }^{\circ} \mathrm{C}$ than between $+21{ }^{\circ} \mathrm{C}$ and $-54{ }^{\circ} \mathrm{C}$ (Table 3), the authors observe consistently a lower decrease of the projectile velocity in the range of the low initial temperatures of propellant than in the range of the high initial temperatures of the propellant.

\subsubsection{Aged Cartridges}

Fig. 12 shows the variation of the maximal pressure inside the cartridge as a function of the ageing time at different initial temperatures of the propellant. The maximal pressure inside the cartridge increases with ageing. This is due to the decrease of the burning rate modifier DBP (dibutylphtalate) concentration at the surface [10]. The importance of the increase of the maximal pressure inside the cartridge with ageing is illustrated in Table 4 by the difference between the maximal pressure inside the cartridge of the propellant (aged 30 days at $+71^{\circ} \mathrm{C}$ ) and the maximal pressure inside the cartridge of the unaged propellant. This increase is greater for the low temperatures $\left(-54{ }^{\circ} \mathrm{C}\right.$ and $-20{ }^{\circ} \mathrm{C}$ ) and can be explained by a likely amplifying effect of grain fracture occurring at low temperature after ageing.

The variation of the velocity of the projectile as a function of the ageing time at different initial temperatures of the propellant is showed in Fig. 13.

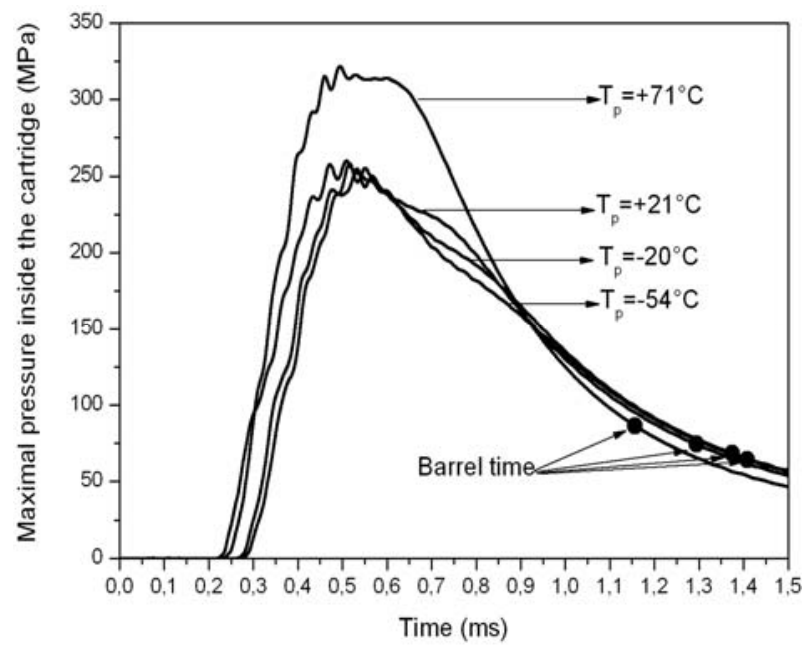

(a)

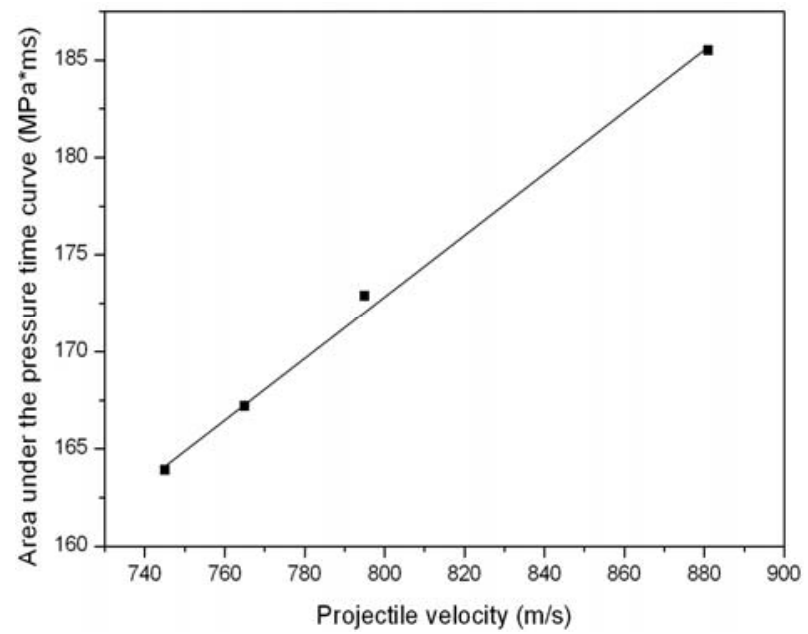

(b)

Fig. 11 (a) Pressure time curves measured in the cartridge (unaged propellant fired at four values of the initial temperature of the propellant); (b) The area under the curve of the cartridge pressure as a function of the projectile velocity. The barrel time is the time that the projectile needs to leave the muzzle. 


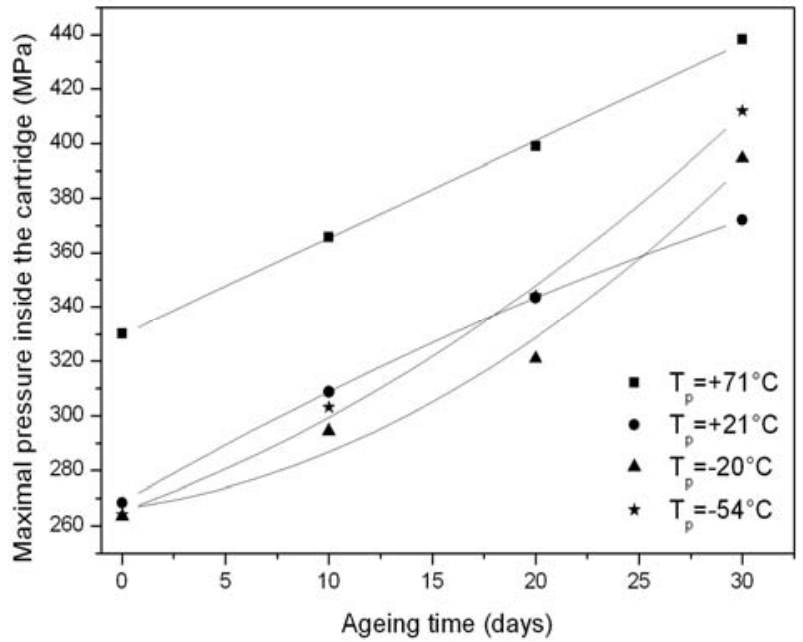

Fig. 12 Variation of the pressure inside the cartridge as a function of the ageing time for four different values of the initial temperature of the propellant.

Table 4 The increase of the maximal pressure inside the cartridge after 30 days of ageing for different initial temperatures of the propellant.

\begin{tabular}{lllll}
\hline$T_{\mathrm{p}}\left({ }^{\circ} \mathrm{C}\right)$ & +71 & +21 & -20 & -54 \\
\hline $\begin{array}{l}\Delta P_{\max } \\
(\mathrm{MPa})\end{array}$ & $108( \pm 12)$ & $104( \pm 12)$ & $131( \pm 15)$ & $148( \pm 21)$ \\
\hline
\end{tabular}

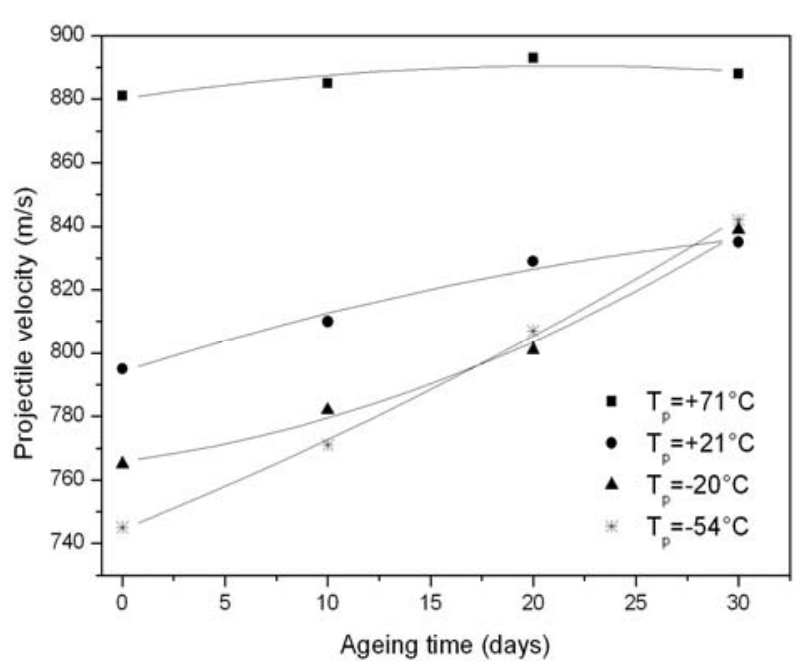

Fig. 13 Variation of the projectile velocity as a function of ageing time at $+71{ }^{\circ} \mathrm{C}$ for four different values of initial propellant temperature.

The significance of the increase of the projectile velocity with ageing is emphasized in Table 5 by the difference between the projectile velocities of the aged propellant (30 days at $+71{ }^{\circ} \mathrm{C}$ ) and unaged. This increase becomes greater as the initial temperature of the propellant decreases. The projectile velocity is considered nearly constant with the ageing time at
Table 5 The increase of the projectile velocity after 30 days of ageing at $+71{ }^{\circ} \mathrm{C}$ for different initial temperatures of propellant.

\begin{tabular}{lllll}
\hline$T_{\mathrm{p}}\left({ }^{\circ} \mathrm{C}\right)$ & +71 & +21 & -20 & -54 \\
\hline$\Delta v(\mathrm{~m} / \mathrm{s})$ & $7( \pm 8)$ & $40( \pm 9)$ & $74( \pm 10)$ & $97( \pm 14)$ \\
\hline
\end{tabular}

$+71^{\circ} \mathrm{C}$, and increase sharply with the ageing time at low temperatures.

For all the initial temperatures of the propellant $\left(+71{ }^{\circ} \mathrm{C},+21{ }^{\circ} \mathrm{C},-20{ }^{\circ} \mathrm{C}\right.$ and $\left.-54{ }^{\circ} \mathrm{C}\right)$, it can be observed that the pressure curve for aged propellants (Fig. 14) has a shape similar to the one of a not deterred propellant (Fig. 4). This is a clear demonstration of the role played by ageing:

- Increase of $P_{\max }$;

- Shortening of the propulsion phase.

All observed parameters are consistent: the combustion rate of the propellant increase with the ageing time in the first part of the pressure-time curve. This results in a shorter time of the combustion and a greater $P_{\max }$ when propellant is aged.

At $+71{ }^{\circ} \mathrm{C}$, the authors speculated that all unaged and aged propellants have the time to burn before that the projectile velocity left the muzzle. With ageing the time of the combustion decreases and then the aged propellants also burn completely before the projectile left the muzzle, resulting in a constant area under the pressure time curve (Table 6). This is consistent with the observed constant projectile velocity as a function of the ageing time (Fig. 13).

The authors speculated also that at ambient and low temperatures, all the unaged propellant does not have the time to burn before that the projectile left the muzzle, with ageing the time of combustion decreases and then the burned fraction of the propellant increases implying an increase of the area under the pressure time curve (Table 6) and an enhance of the projectile velocity (Fig. 13).

4.2.3 Temperature Coefficient of the Maximal Pressure and Projectile Velocity

The temperature coefficients of the maximal pressure and projectile velocity are defined similarly to the temperature coefficient of the combustion rate 


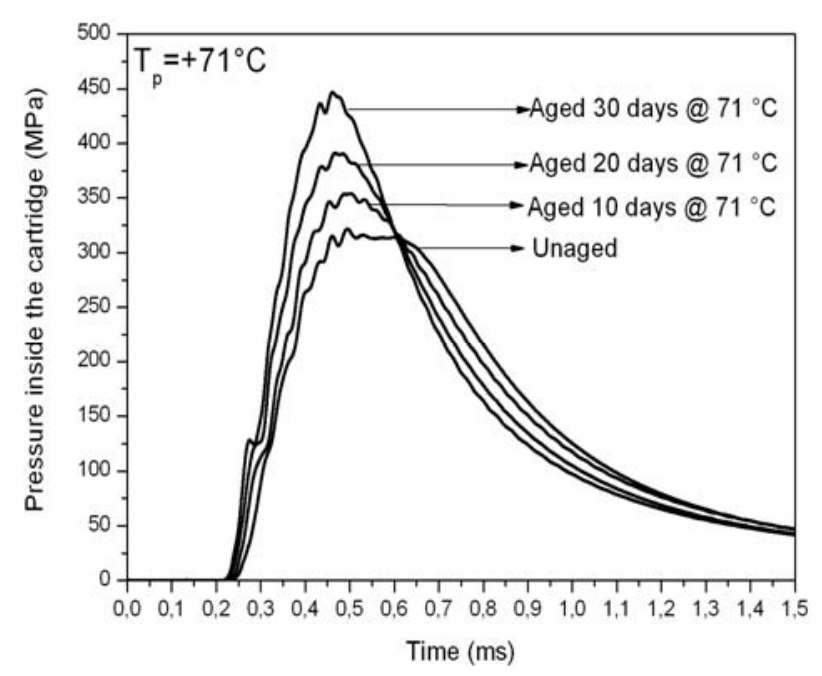

(a)

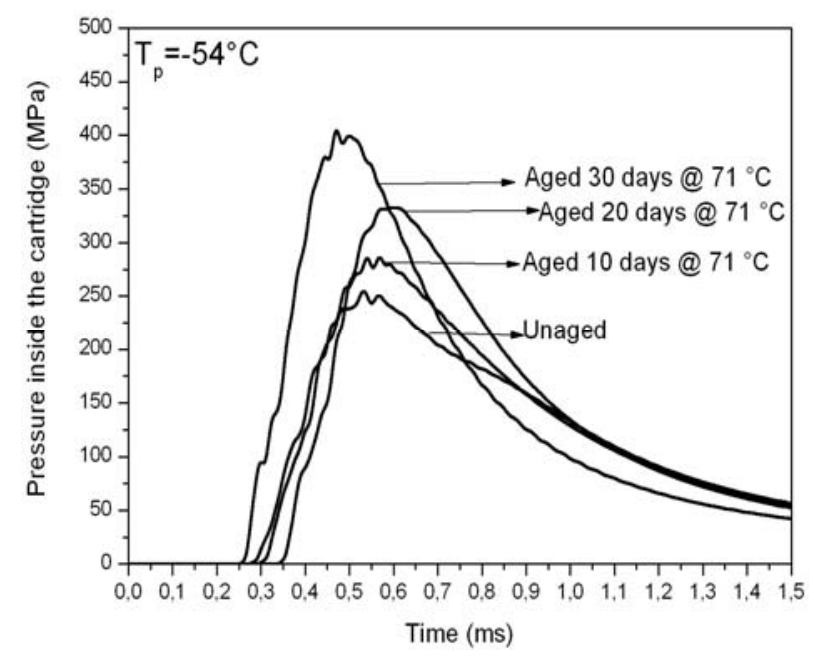

(b)

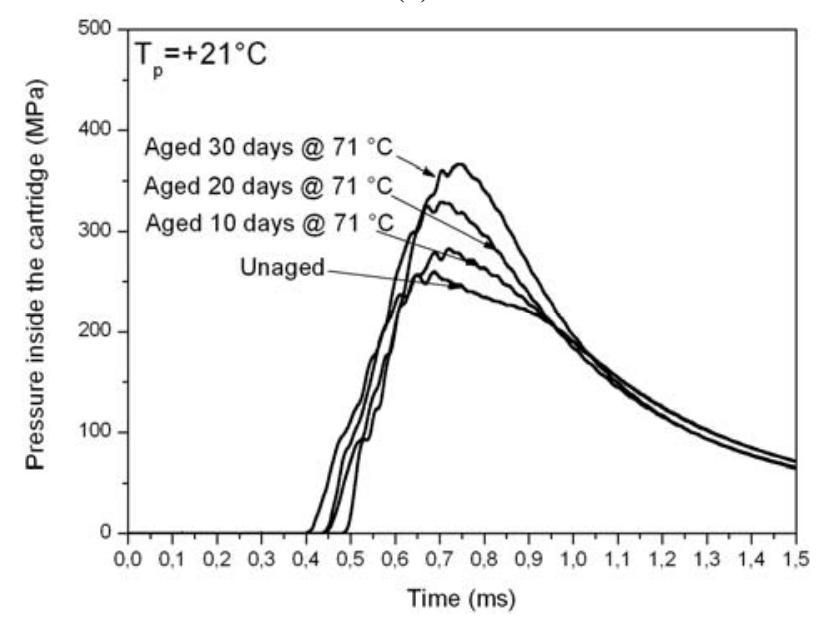

(c)

Fig. 14 Pressure time curves measured inside the cartridge during the ballistic firing as a function of ageing time. (a) The propellant temperature is equal to $+71{ }^{\circ} \mathrm{C}$; (b) The propellant temperature is equal to $-54{ }^{\circ} \mathrm{C}$; (c) The propellant temperature is equal to $+21^{\circ} \mathrm{C}$. (shown in the part of 4.1.3). Table 7 summarizes the hot and cold temperature coefficients of the maximal pressure and projectile velocity of the unaged and aged propellants. The largest temperature coefficients of the maximal pressure and projectile velocity are observed in the range of the high temperatures.

\subsection{Impact Tests}

\subsubsection{Impact Sensitivity Tests}

The results of impact tests according to Bruceton "up and down" method are pictured in Fig. 15. It is observed that the obtained $\mathrm{H}_{50}$ increases as the initial temperature of the propellant decreases. In this case, the propellant needs less energy of impact to ignite as the initial temperature of the propellant increases. So, the propellant becomes more sensible to impact stimulus when the initial temperature of the propellant enhances.

\subsubsection{Mechanical Properties}

Fig. 16 shows picture of a spherical propellant before and after impact obtained with reflection lighting. After impact, the spherical particle looks like a flattened one. Some grain fractures (Fig. 17) are observed after impact. Qualitatively, no discrepancies are observed between the number of the grain fracture at low or high temperature.

Influence of the initial temperature of the propellant and ageing time on the grain deformation is showed in Fig. 18. In the case of the unaged propellant, a sharp increase of the deformation is observed at low temperature. With ageing the deformation increases, specifically at high and ambient temperatures.

\subsection{Correlation between the Various Approaches}

In Fig. 19, the maximal pressure inside the cartridge is plotted as a function of the combustion rate at 40 MPa. It can be observed that the maximal pressure inside the cartridge increases with the combustion rate at $40 \mathrm{MPa}$. This confirms that the variation of the maximal pressure inside the cartridge depends on the combustion rate and therefore on the deterrent concentration in surface. 
Table 6 Values of the area under the curve of the pressure inside the cartridge versus time at $+71^{\circ} \mathrm{C},+21{ }^{\circ} \mathrm{C}$ and $-54{ }^{\circ} \mathrm{C}$ for different ageing times.

\begin{tabular}{lllll}
\hline \multirow{2}{*}{$T_{\mathrm{p}}\left({ }^{\circ} \mathrm{C}\right)$} & \multicolumn{3}{l}{ Int $(\mathrm{MPa} * \mathrm{~ms})$} & \\
\cline { 2 - 5 } & Unaged & Aged 10 days at $71^{\circ} \mathrm{C}$ & Aged 20 days at $71^{\circ} \mathrm{C}$ & Aged 30 days at $71^{\circ} \mathrm{C}$ \\
\hline+71 & $188( \pm 2)$ & $191( \pm 2)$ & $189( \pm 2)$ & $189( \pm 2)$ \\
+21 & $173( \pm 1)$ & $178( \pm 2)$ & $186( \pm 2)$ & $190( \pm 1)$ \\
-54 & $164( \pm 2)$ & $170( \pm 1)$ & $176( \pm 2)$ & $186( \pm 3)$ \\
\hline
\end{tabular}

Table 7 Hot and cold temperature coefficients of the maximal pressure and projectile velocity of the unaged and aged propellant.

\begin{tabular}{lll}
\hline Propellant & Pressure $\left(\mathrm{MPa} /{ }^{\circ} \mathrm{C}\right)$ & \\
\hline & Hot & Cold \\
\hline Unaged propellant & & \\
\hline$P_{\max }\left(\mathrm{MPa} /{ }^{\circ} \mathrm{C}\right)$ & 1.234 & 0.060 \\
$v\left(\mathrm{~m} / \mathrm{s} /{ }^{\circ} \mathrm{C}\right)$ & 1.720 & 0.666 \\
\hline Aged 10 days @ $+71^{\circ} \mathrm{C}$ & & 0.075 \\
\hline$P_{\max }\left(\mathrm{MPa} /{ }^{\circ} \mathrm{C}\right)$ & 1.138 & 0.520 \\
$v\left(\mathrm{~m} / \mathrm{s} /{ }^{\circ} \mathrm{C}\right)$ & 1.500 & \\
\hline Aged 20 days @ $+71^{\circ} \mathrm{C}$ & & -0.008 \\
\hline$P_{\max }\left(\mathrm{MPa} /{ }^{\circ} \mathrm{C}\right)$ & 1.112 & 0.293 \\
$v\left(\mathrm{~m} / \mathrm{s} /{ }^{\circ} \mathrm{C}\right)$ & 1.280 & \\
\hline Aged 30 days @ $+71^{\circ} \mathrm{C}$ & & -0.533 \\
\hline$P_{\max }\left(\mathrm{MPa} /{ }^{\circ} \mathrm{C}\right)$ & 1.324 & -0.093 \\
$v\left(\mathrm{~m} / \mathrm{s} /{ }^{\circ} \mathrm{C}\right)$ & 1.060 & \\
\hline
\end{tabular}

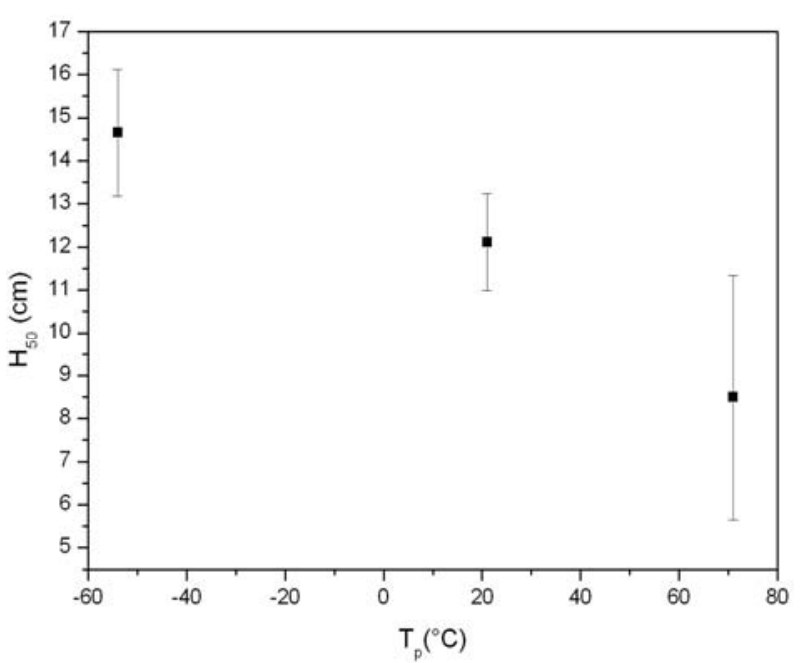

Fig. 15 Impact sensitivity data $\left(\mathrm{H}_{50}\right)$ according to Bruceton "up and down" method as a function of the initial temperature of the unaged propellant. The displayed error bars are +1 SD.

The observed temperature coefficients of the combustion rate, the maximal pressure and the projectile velocity are consistent: the largest temperature coefficients are always observed in the range of the high temperatures.

A sharp increase of the deformation is observed at low temperature before and after ageing (Fig. 18), it is likely that the mechanical properties are lower in the range of the cold temperatures. The authors speculate that this may amplify the effect of the grain fracture at low temperature. This is consistent with the observed increase of the maximal pressure at low temperatures (Fig. 9 and Table 4).

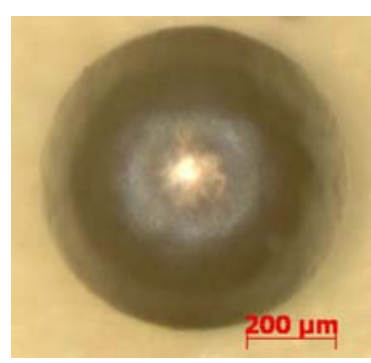

(a)

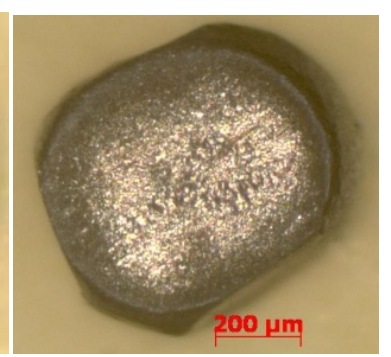

(b)
Fig. 16 (a) Photo microscopy of a spherical propellant particle before impact; (b) Photo microscopy of a spherical propellant particle after impact. The initial temperature of propellant is equal to $+21^{\circ} \mathrm{C}$. 


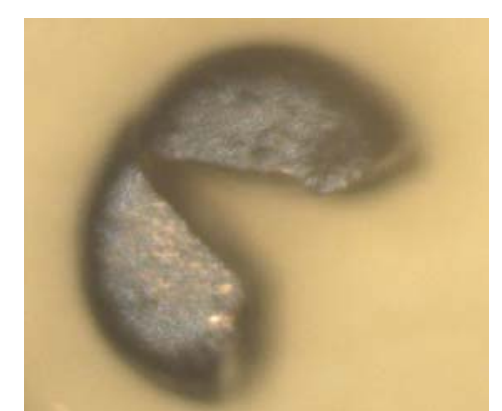

Fig. 17 Photo microscopy of a fractured propellant particle after impact. The initial temperature of the propellant is equal to $-54{ }^{\circ} \mathrm{C}$.

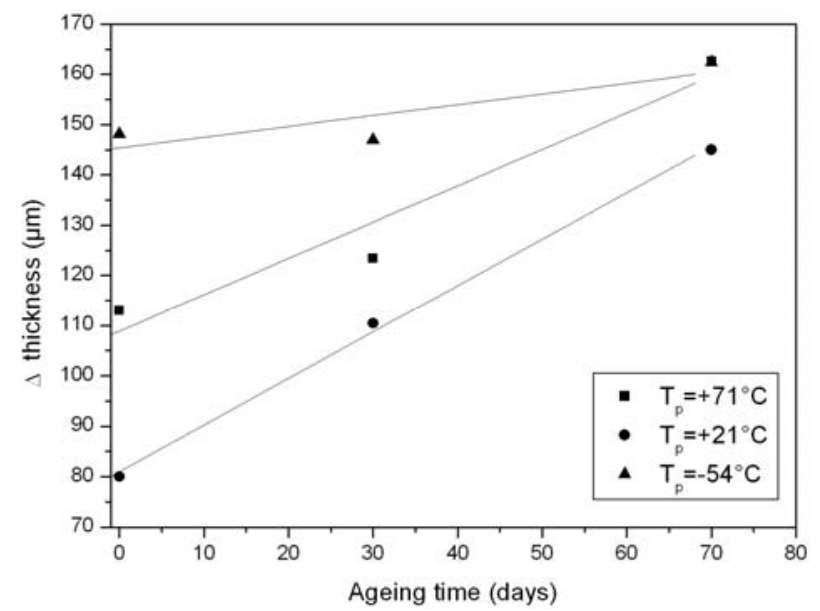

Fig. 18 Variation of the average thickness as a function of the ageing time at three values of the propellant temperature.

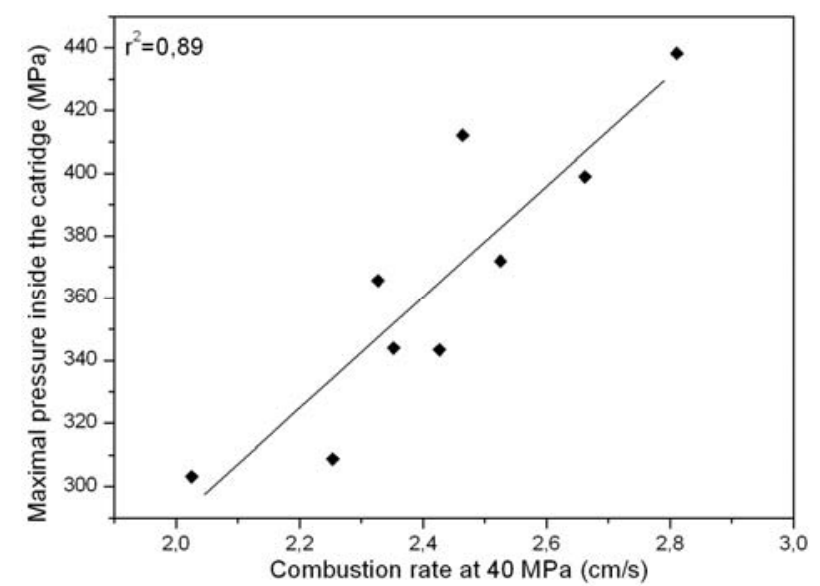

Fig. 19 Variation of the maximal pressure inside the cartridge and the as a function of the combustion rate at $\mathbf{4 0}$ MPa.

\section{Conclusions}

The impact of the initial temperature of the propellant on its ballistic properties, mechanical integrity and sensitivity has been monitored by firing 5.56 cartridges, closed vessel tests and fallhammer impact tests.

Closed vessel tests showed that the combustion rate of the deterred and the not deterred part of the propellant decreases as the initial temperature of the propellant decreases.

Ballistic firing of 5.56 cartridges and closed vessel tests showed that the largest temperature coefficients are obtained in the range of the high initial temperatures of the propellant.

The impact tests according to Bruceton "up and down" showed that the propellant becomes more sensible to impact stimulus when the initial temperature of the propellant enhances.

The response of the propellant grain to the impact stimulus showed a sharp increase of the deformation observed at low temperature before and after ageing. The authors speculated that the mechanical properties are lower in the range of the cold temperatures.

\section{Acknowledgements}

The author (Karim Moulai Boulkadid) thanks the Polytechnic Military School (EMP, Algiers, Algeria) for the financial support of the Ph.D. formation and the ballistic laboratory of PB Clermont for the access to the ballistic firing equipment, as well as for the technical support.

\section{References}

[1] Oberle, W., and White, K. 1997. The Application of Electrothermal-Chemical (ETC) Propulsion Concepts to Reduce Propelling Charge Temperature Sensitivity. ARL-TR-1509, U.S. Army Ballistic Research Laboratory, Aberdeen Proving Ground, MD 21005-5066.

[2] Clifford, W. 1982. Temperature Sensitivity of Aircraft Cannon Propellants. AFATL-TR-82-72.

[3] Clifford, W., and Bertram, K. 1982. Ballistic criteria for Propellant Grain Fracture in the GAU-8/A 30 MM Gun. AFATL-TR-82-21.

[4] Jeunieau, L., Lefebvre, M. H., Papy, A., Pirlot, M. C. Guillaume, P., and Reynaud, C. 2002. "Closed Vessel Test: Influence of the Ignition Method on the Combustion Rate.” In 33th International Annual Conference of ICT, 
Karlsruhe.

[5] STANAG 4115. 1997. Definition and Determination of Ballistic Properties of Gun Propellants. North Atlantic Council.

[6] Jeunieau, L., Lefebvre, M. H., Papy, A., Pirlot, M. C., Guillaume, P., and Reynaud, C. 2003. "Spherical Deterred Propellant: Influence of the Concentration Gradient on the Burning Rate Calculation.” In 34th International Annual Conference of ICT, Karlsruhe.

[7] Jeunieau, L., Lefebvre, M. H., and Guillaume, P. 2007. "Ballistic Stability of a Spherical Propellant: Comparison with a Flattened Spherical Propellant.” Central European
Journal of Energetic Materials 4 (1-2): 31-44.

[8] EN 13631-4. 2003. Explosives for Civil Uses-High Explosives-Part 4: Determination of Sensitiveness to Impact of Explosives. European Committee for Standardization, 2002.

[9] STANAG 4489. 1999. Explosives, Impact Sensitivity Tests. NATO Standardization Agreement.

[10] Jeunieau, L., Lefebvre, M. H., Guillaume, P., Wilker, S., Chevalier, S., and Eibl, S. 2004. "Stability Analyses of Rolled Ball Propellants, Part II-Ballistic Stability.” In 35th International Annual Conference of ICT, Karlsruhe, pp. 15-28. 